year period this strength should be used. Also, if the primary health care team is involved early, it is in a better position to provide continuing support for couples and families later found to be "at risk." General practice provides an opportunity for later targeted cascade screening-that is, investigating close relatives of people who have screened positive. ${ }^{16}$

The rationale for genetic screening services is to provide patients with informed choice. Some doctors voice the understandable concern that demand does not exist for these services. But recently $86 \%$ of older schoolchildren favoured screening for cystic fibrosis carrier status. ${ }^{9}$ In Trent region, antenatal patients have responded favourably to offers of screening for cystic fibrosis discussed opportunistically by a general practitioner ( $J$ W Fenby-Taylor, personal communication) and to screening for the haemoglobinopathies.

The primary care team's role goes beyond genetic screening tests; drawing an accurate family tree must be developed as an essential basic skill. ${ }^{11}$ Family histories have begun to be recorded in family practices in North America and are often pictorially represented as a genogram..$^{12}$ Patients and general practitioners can successfully collect basic genetic information. ${ }^{6}$ Recording of the pedigree in primary health care would also be useful in deciding whom to refer to genetics services.

Information on families has to be collected and recorded within a reasonable time. ${ }^{10}$ Two techniques have been considered: the self administered family history questionnaire (which takes one to two hours ${ }^{13}$ ) and the structured interview (which takes about 20 minutes. ${ }^{12}$ ) Furthermore, we are extremely impressed by our patients' ability to understand pedigrees and suggest that the value of family trees prepared by patients should be researched. We need to be confident that patients' recall is accurate and that the yield of information is worthwhile; research suggests that this is likely. ${ }^{14}{ }^{15}$ In this district we are evaluating new approaches to collaboration between general practitioners and geneticists in providing a service to a specific ethnic minority group.

The timing of the recording of the family history may be important. Although some authors advocate incorporating this into the preconceptional screening services offered to patients, older members of the family may be required to confirm and extend the information.

After such enthusiasm a few notes of caution should be sounded. Firstly, patients need to be informed fully of the consequences-for example, the implications of presymptomatic genetic screening for life insurance. ${ }^{16}$ Secondly, a recent circular from the Department of Health states that future genetic services will have to be funded from present resources. Genetic services in primary care require financial backing; above all, funding for population screening should not be based on targets (as occurs for cervical cytology) as this could lead to unintentional pressure to offer the service ("supply push") at the detriment of a person's informed choice to opt out of screening.

The primary care team should have the genetic knowledge and counselling skills to offer pre-test counselling and to record family information (Modell recommends that one member of the team should be specially trained for this $\left.{ }^{1}\right),{ }^{6}$ and collaboration with departments of clinical genetics should allow coordination of post-test counselling. In this way the general practitioner would act as a filter to specialised genetic services, ensuring their most efficient use.

N QURESHI

Department of General Practice, Honorary research fellow

Medical School,

Queen's Medical Centre,

Nottingham NG7 2UH

J A RAEBURN

Centre for Medical Genetics,

City Hospital,

Nottingham NG5 1PB

Professor of clinical genetics

1 Modell M. Screening for carriers of cystic fibrosis-a general practitioner's perspective. $B M f$ 1993;307:849-52.

2 Baird PA, Anderson TW, Newcombe HB, Lowry RB. Genetic disorders in children and young dults: a population study. Am f Hum Genet 1988;42:677-93.

3 Royal College of Physicians of London. Prenatal diagnosis and genetic screening: community and service implications. London: RCP, 1989.

Angastiniotis M, Kyriakidou S, Hadjiminias M. How thalassaemia was controlled in Cyprus. World Health Forum 1986;7:291-7.

5 Bekker H, Modell M, Denniss G, Silver A, Mathew C, Bobrow M, et al. Uptake of cystic fibrosis carrier testing in primary care: supply push or demand pull? BMF 1993;306:1584-7.

6 Harris H, Scotcher D, Hartley N, Wallace A, Craufurd D, Harris R. Cystic fibrosis carrier testing in early pregnancy by general practitioners. $B M F 1993 ; 306: 1580-3$.

7 Burn J. Screening for cystic fibrosis in primary care. BMf 1993;306:1558-9.

8 Firth HV, Lindenbaum RH. UK clinicians' knowledge of and attitudes to the prenatal diagnosis of single gene disorders. 7 Med Genet 1992;29:20-3.

9 Cobb E, Holloway S, Elton R, Raeburn JA. What do young people think about screening for cystic fibrosis? 7 Med Genet 1991; 28:322-4.

10 Zander LI, Beresford SAA, Thomas P. Medical records in general practice. London: Royal College of General Practitioners, 1978. (Occasional paper No 5.)

11 Royal College of Physicians of London. Teaching genetics to medical students. London: RCP, 1990.

12 Rogers J, Durkin M. The semi-structured genogram interview. I: Protocol, II: Evaluation. Family Systems Medicine 1984;2:176-87.

13 Cole J, Conneally PM, Hodes ME, Merritt AD. Genetic family history questionnaire. 9 Med Genet 1978;15:10-8.

14 Love RR, Evans AM, Josten DM. The accuracy of patients' reports of a family history of cancer. $f$ Chronic Dis 1985;4:289-93.

15 Langer A, Kudart E. Construction of a family pedigree in genetic counselling before amniocentesis. f Reprod Med 1990;35:715-8.

16 Harper PS. Insurance and genetic testing. Lancet 1993;341:224-7.

\title{
Presenting expert evidence in criminal proceedings
}

\section{Recommendations will help expert witnesses}

Presenting evidence in criminal courts can be stressful and even intimidating. In the wake of recent serious miscarriages of justice, highlighted by the release of the Guildford four and the Birmingham six in particular, the Royal Commission on Criminal Justice has investigated in detail the role of expert evidence in criminal cases. ${ }^{1}$ Although scientific evidence has come under particularly close scrutiny, the commission has emphasised that the objectivity and presentation of all expert evidence are important, from whichever discipline it comes.

The commission has accepted that scientific evidence has not always been presented in such a way that counsel, judges, and juries have been able to understand its nature and meaning. Its recommendations aim to ensure that evidence is presented by properly qualified experts who perform this task objectively and impartially and that the quality of evidence should conform to measurable standards whenever possible.

Because of the need for expert witnesses to understand legal as well as scientific issues the commission has recommended the development of specific qualifications over and above professional qualifications to allow courts to assess the competence of experts. It acknowledges, however, that any new qualifications could never be more than desirable additions to professional qualifications. It also recommends that visits to laboratories should be part of the vocational 
training of barristers and that both counsel and experts should be trained to use visual aids in court.

One of the commission's main recommendations for preventing miscarriages of justice is the development of forensic science as an established scientific discipline. The commission has endorsed the recommendations of a recent Home Office working party, which covered the development of career structures, new senior lecturer posts, and an extended list of forensic pathologists. ${ }^{2}$ It also supports the new Advisory Board for Forensic Pathology, set up in 1991. The commission recommends a new Forensic Science Advisory Council to carry out external audits of forensic science laboratories and to ensure the proper training of forensic scientists.

Forensic laboratory procedures are likely to be accredited under the existing National Measurement Accreditation Service, a process that has already begun. In future, laboratory accreditation may depend on demonstrably high standards in interpreting scientific facts as well as in performing the tests themselves.

Encouragingly for medical expert witnesses, who are often baffled by the complexities of plea bargaining and court craft, the commission has recognised that the trial process is not suited to the objective presentation of expert evidence. The commission heard from many experts that prosecution and defence lawyers are often ill prepared to deal with scientific issues. ${ }^{3}$ In response to this the commission has identified the pretrial phase as the appropriate time to sort out and define scientific issues and to recommend appropriate tests. This should mean more pretrial conferences between prosecution and defence counsel and experts; pretrial hearings; and much more reliance on written evidence from experts. The objective is the agreement and interpretation of expert evidence as far as is reasonably possible so that the trial concerns itself only with the remaining contentious issues. When there is contention about expert evidence the pretrial phase should be used to narrow these differences.

\section{Challenges to expert evidence are common}

The commission found that between $30 \%$ and $40 \%$ of crown court trials included the presentation of expert evidence (in England and Wales this amounts to about 10000 trials a year). In about a quarter of these the prosecution's expert evidence is challenged by the defence. Importantly, the commission found that in about 120 cases a year the prosecution did not have enough time to complete the appropriate tests. ${ }^{4}$

Although the commission has recognised that there is no need for experts to give evidence from the witness box if their evidence has been agreed by both sides beforehand, it is adamant that experts should be obliged to express the limitations of their evidence. Experts should disclose information about tests, investigations, interpretations, and other scientific issues that relate to the case and that tend to disprove or cast doubt on the opinions they are expressing.

After giving evidence many expert witnesses consider that scientific issues have been misunderstood or that they have not had sufficient opportunity to tell the court about the salient points of relevant research. The commission has therefore recommended that trial judges should give experts the opportunity to expand or clarify issues they believe have not been adequately covered before they leave the witness box-if necessary, in the absence of the jury. Furthermore, after leaving the box, experts should be encouraged to tell their solicitors if they think the evidence has not been presented clearly so that this can be communicated to the court.

The commission considered but rejected a proposal that experts should be employed in public sector forensic science laboratories and should be independent of the prosecution and the defence. This was rejected because of the possible confusion of roles, as has happened with police surgeons. ${ }^{5}$ The commission also rejected a proposal that the courts should appoint expert witnesses because there could be no guarantee that the evidence given by a court expert would be any better than that presented by the prosecution or the defence. Furthermore, the appointment of a court expert might limit the opportunity of the defence or the prosecution to lead its own evidence, and if the court expert sat with the judge as an assessor the expert would not be available for cross examination.

A proposal for an accreditation system for expert witnesses and a register that would be kept by a government department was also rejected. The commission did recommend, however, that professional bodies should help the courts by maintaining a register of their members who were suitably qualified to act as expert witnesses. Professional bodies would give advice to legal representatives about the qualifications that witnesses should hold if they were to be considered an expert in a particular discipline.

Although no specific recommendations in medicine have been made, this role could be assumed by the royal colleges or advisory committees on specialist training. The commission acknowledged, however, that no professional body could be expected to guarantee the competence of particular individuals. A code of practice in relation to professional ethics and disclosure of expert evidence has been recommended, and the forensic science service has already produced a code of practice.

Although no such code of practice has yet been developed for medicine or dentistry, the overall recommendations of the royal commission, if implemented, should do much to help expert witnesses to present their evidence more effectively whether they appear in court regularly or once in a lifetime.

JONATHAN P SHEPHERD Professor of oral and maxillofacial surgery

University of Wales College of Medicine,

Cardiff CF4 4XY

1 Royal Commission on Criminal Justice. Report. London: HMSO, 1993.

2 Wasserman GJ. Repont of the working party on forensic pathology. London: HMSO, 1989.

Roberts $\mathrm{P}$, Willmore $\mathrm{C}$. The role of forensic science evidence in criminal proceedings. London: HMSO, 1993.

M. Henderson P. The crown court study. London: HMSO, 1993.

5 Three-faced practice: doctors and police custody. Lancet 1993;341:245-7. 